Fenoll Pellín, Alberto.

Profesor de Educación Secundaria; especialidad Dibujo;

Departament d'Ensenyament de la Generalitat de Cataluña.

\title{
La escultura pública en el proceso de remodelación del viejo cauce del río Turia en Valencia, 1974-2014.
}

\section{The public sculpture in the renovation process of the Turia's old riverbed in Valencia, 1973-2014.}

TIPO DE TRABAJO:

Comunicación.

PALABRAS CLAVE:

Escultura, urbanismo, Turia, Valencia.

KEY WORDS:

Sculpture, urbanism, Turia, Valencia.

\section{RESUMEN}

El Turia deja una huella indeleble unida a la ciudad de Valencia por la trascendencia que ha tenido en su configuración espacial y en el devenir de su tiempo. Esto se refleja en la transformación sufrida por el cauce del río, que pasa de ser un espacio natural a un jardín urbano, remodelando la imagen de Valencia en un proceso donde interviene con singular aportación la Escultura.

El trabajo de investigación titulado, La escultura pública en el proceso de remodelación del viejo cauce del río Turia en Valencia, 1973-2014, hace un inventario y cataloga las esculturas que se encuentran en dicho espacio. El objetivo principal es abordar un estudio de los planes de actuación escultórica durante el ajardinamiento del antiguo cauce del río, así como la gestión de las intervenciones, considerando la obra en su entorno y decurso histórico.

El análisis exhaustivo de las informaciones obtenidas y debidamente contextualizadas, permite construir el relato que hay detrás de cada escultura y que forma parte del acontecer del viejo cauce. Podemos clasificar en tres tipos las actuaciones escultóricas llevadas a cabo: al margen de los planes oficiales, intervenciones bajo proyectos institucionales y las incluidas en diseños de ajardinamiento.

Los resultados obtenidos constatan la inexistencia de un proyecto conjunto del espacio, que acaba con una diseminación de esculturas a lo largo del recorrido, fruto de la ocurrencia y de la falta de planificación. Esto ha propiciado una despreocupación progresiva en el tiempo que perjudica gravemente al estado de las esculturas y su exhibición.

Este estudio pretende, con los resultados obtenidos, valorar la tesitura actual de la escultura en dicho lugar, y que pueda servir para introducir una reflexión sobre el sentido que se pretende conferir en un futuro a la escultura pública en el espacio urbano, y específicamente en la ciudad de Valencia. 


\section{ABSTRACT.}

The river Turia leaves an indelible mark on the city of Valencia because of the importance that it has had on the spatial shape of the city and on its historical passing of time. This is reflected in the riverbed deep transformation, moving from being a natural space to a big urban garden and reshaping Valencia's image. This is a process in which the Sculpture is involved as a unique contribution.

The research work, named The public sculpture in the renovation process of the Turia's old riverbed in Valencia, 1973-2014 does an inventory and catalogues sculptures which are located in this space. The principal task is tackling a study of the sculptural action plan, adopted in the course of the old riverbed landscaping, as well as the interventions' management, taking into account their environment and their historical development.

The exhaustive analysis of the information collected and contextualized with its historical happening will allow us to build a story of every sculpture which is part of the old riverbed's story. The sculptural action plans carried out can be classified into three types: outside the official plans; sculptural action inside the official plans, and sculptural actions included in landscaping design.

The results obtained confirm that there is no joint space project, and this finishes with a dissemination sculptures along the way. This is not a result of any plan but improvisation that has led it to a progressive lack of concern over time and this damages seriously the state of the sculptures and their exhibition.

The research aims to assess the results obtained from the current circumstance of sculpture in this specific place and it will help us to introduce a reflection about the future sense of the public sculpture in urban areas, particularly in the city of Valencia.

\section{CONTENIDO.}

En octubre de 1957, una crecida del río Turia asoló Valencia. Este trágico acontecimiento fue decisivo para desviar definitivamente el curso del río fuera del casco urbano. Finalmente, en 1972 se inauguró el nuevo cauce del río Turia que dejaría libre el viejo lecho fluvial del curso de agua.

El antiguo cauce del Turia es un corredor urbano que atraviesa la ciudad de oeste a este, y en aquellos años era idóneo para solucionar los múltiples problemas urbanísticos que tenía Valencia. Por ello, estos terrenos fueron objeto de varios proyectos que especulaban sobre sus usos y funciones y que entre otros, planearon la construcción de una red de comunicación vial por el interior del cauce. Dicha intención disintió de los deseos de la práctica totalidad de la sociedad valenciana de los años setenta, que bajo la popularizada consigna "El llit del Túria és nostre i el volem verd", deseaba la conversión del antiguo cauce en un parque. En estas movilizaciones de carácter popular en las que participaba buena parte de la ciudadanía, en varias ocasiones acababan con plantaciones masivas de árboles en el interior del viejo cauce, mayoritariamente en dos sectores, uno entre los puentes de San José y de Serranos y el otro en los aledaños del puente del Real.

Entre el ambiente optimista de aquellos plantíos, en 1973, un estudiante argentino de arte llamado Silvio Moraira, decide apoyar aquellas acciones populares y solicita al Organismo municipal de Parques y Jardines tallar algunas de las piedras que se encontraban en el desecado cauce. El personal municipal accedió, y Moraira escogió cuatro piedras en las inmediaciones del puente de Serranos con las que elaboró otras tantas esculturas. Estas tallas se convirtieron en la primera intervención escultórica que se realizó en el interior del antiguo cauce desde que el Turia abandonase su lecho natural. 


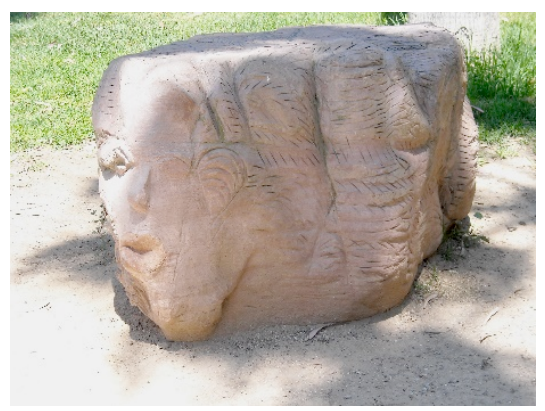

La mujer. Silvio Moraira, 1973.

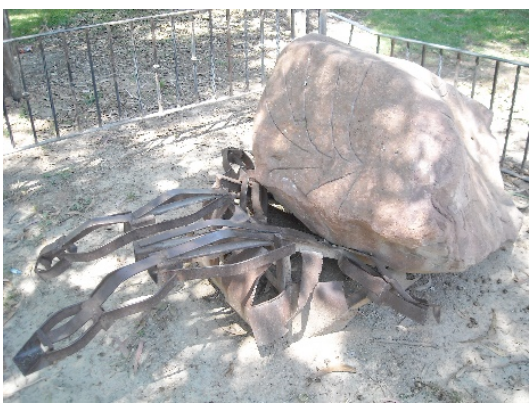

El viejo. Silvio Moraira, 1973.

Gracias a aquellas movilizaciones sociales, en junio del mismo año, el Ministerio de Obras Públicas anunció que el viejo cauce del río sería finalmente un espacio verde.

Durante los años siguientes, el proceso de remodelación del viejo cauce se vio favorecido por el cambio hacia la democracia que estaba experimentando el país en aquel momento, ante las primeras elecciones municipales democráticas celebradas en España en 1979. La nueva corporación del Ayuntamiento de Valencia se posicionó a favor de transformar el antiguo lecho en zona verde, y lleva a cabo varias acciones para recoger ideas sobre el futuro parque.

En septiembre de 1981, el Consistorio valenciano contrata al Taller de arquitectura de Ricardo Bofill para redactar el Avance del Plan Especial de Reforma Interior del río Turia. El anteproyecto se presenta a la ciudadanía en julio de 1982 con una exposición celebrada en la Lonja. Este trabajo tenía un marcado carácter neoclásico y por ello, desde varios sectores profesionales y vecinales entre otros, el proyecto recibe críticas que tuvieron como denominador común el exceso de arquitectura y planificación del jardín. Tras una labor conjunta entre el Ayuntamiento y el Taller de Bofill, a finales de 1984 termina de redactarse el documento definitivo del Plan Especial de Reforma Interior (PERI) del viejo cauce del Turia. Según este, el proyecto tendría un plazo de ejecución de diez años, además de un carácter abierto al tratarse de un plan esencialmente flexible. Por esta razón, los diseños de los dieciocho tramos en los que se divide el viejo cauce serían encargados a distintos profesionales valencianos, que aportarían sus ideas de acuerdo a las líneas marcadas por el $P E R I^{1}$.

En febrero de 1985, el colectivo de arquitectos Vetges Tu i Mediterrània es seleccionado para diseñar el tramo II, comprendido entre el assut de Rovella y el puente de Campanar. El proyecto destaca por el carácter lúdico en el tratamiento del agua y los espacios verdes. Desde el principio se pensó en realizar una intervención artística, y por ello propusieron al artista valenciano Artur Heras colaborar en el proyecto. Se optó por representar un bodegón escultórico que reflejase el entorno urbano en el que se enmarcaba el jardín, al tiempo que contribuyese a mantener la presencia simbólica del curso del agua. Así fue como Heras realiza en 1987 la escultura-fuente Taulatetombant instalada junto al puente de Campanar. La obra forma parte de la estrategia del diseño para mejorar la ruda estética del puente, lanzando desde sus más de 10 metros de altura un chorro de agua que se precipita a un estanque situado a los pies del viaducto. El fin es centrar la mirada del visitante sobre la escultura, atenuando así la presencia del puente ${ }^{2}$.

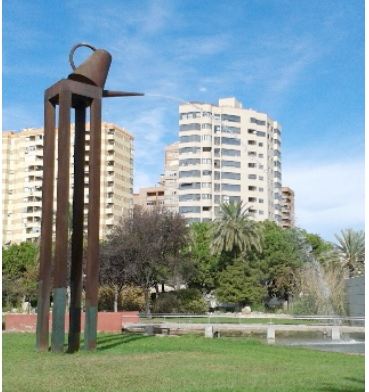

Taulatetombant. Artur Heras, 1987.

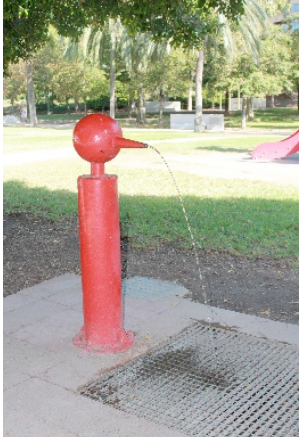

La fonteta de la veritat. Artur Heras, 1987

\footnotetext{
${ }^{1}$ Memoria PERI, pp. 4-7.

${ }^{2}$ FENOLL PELLíN, A. La escultura pública en el proceso de remodelación del viejo cauce del río Turia en Valencia, 1973-2014. Tesis doctoral UPV. Valencia, 2015.
} 
La colaboración de Heras se completa con el diseño de otra fuente-bebedero inspirada en el personaje de Pinocho. Está resuelta de forma muy simple y su característica nariz se convierte en el caño por donde se bebe.

En la segunda mitad de los años ochenta, el proceso de remodelación del viejo cauce atraviesa graves dificultades de financiación, al tiempo que recibe críticas sobre su gestión, procedentes de diversos sectores profesionales, vecinales y de los grupos de la oposición municipal. Sin embargo, en enero de 1989, la remodelación tomaría un nuevo rumbo tras anunciarse por parte del Ayuntamiento cambios en la gestión del proceso, liquidando definitivamente el proyecto desarrollado por Bofill. Las nuevas actuaciones serían más sencillas, con menos arquitectura y un ajardinamiento más mediterráneo. El objetivo era conseguir un menor coste de realización del parque y un mantenimiento más sostenible.

A finales de 1989, el artista danés Per Kirkeby proyecta un specific site de carácter permanente para Valencia, con motivo de la muestra que sobre este, acoge el Institut Valencià d'Art Modern (IVAM) Centre del Carme. La obra de ladrillo se levantaría en el tramo V, frente al recién construido Centre Julio González.
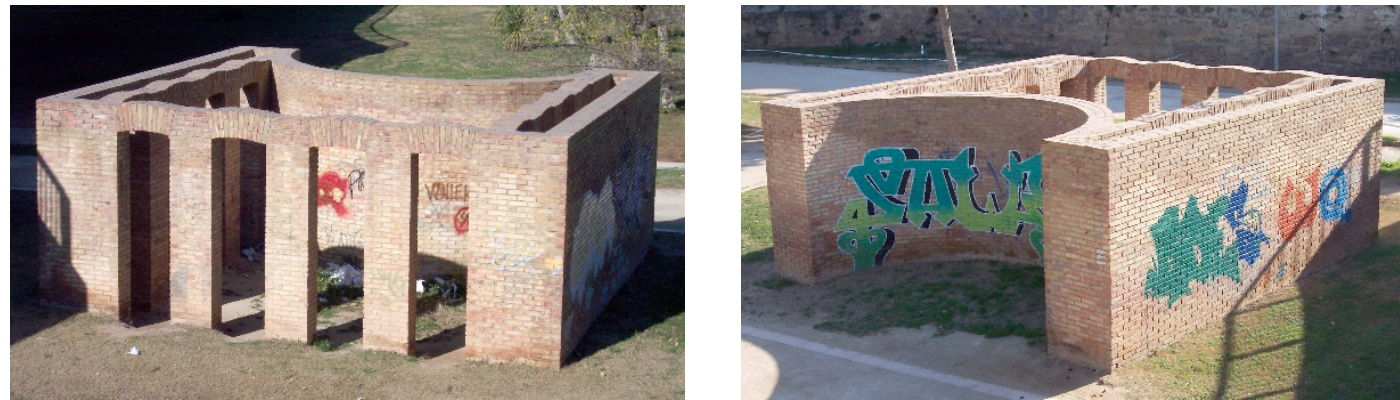

Sin título. Per Kirkeby, 1989.

La prensa se hizo eco de la instalación y anunciaba que sería la primera obra de un futuro parque escultórico ubicado en dicho tramo, donde se recogerían otras piezas de diversos artistas contemporáneos ${ }^{3}$. Aunque finalmente, dicho proyecto nunca llegó a formalizarse.

Unos años más tarde, dentro de las actividades programadas por Movimiento-Inercia ${ }^{4}$ en mayo de 1996, se llevaría a cabo una nueva intervención escultórica localizada también en el tramo V. Consistió en la realización de un banco tallado en piedra, y la responsable del proyecto fue la artista suiza Claudia Ammann junto al profesor de la Facultad de Bellas Artes de la UPV Sebastián Miralles. La acción no obtuvo ninguna ayuda institucional, y en ella participaron voluntariamente un grupo de estudiantes belgas y españoles entre otros. La idea tuvo como propósito realizar un trabajo cooperativo donde el arte fuese el catalizador que cristalizara los deseos y los modos de hacer de las personas que intervinieron.

Pasados unos años, en 1999, comenzaría la remodelación de los tramos XIII y XIV, ubicados frente a la Ciudad de las Artes y las Ciencias (CAC), y diseñados por el arquitecto Jacobo Ríos y el ingeniero técnico agrícola Ángel Palomar. Según los autores, la coherencia y unidad del proyecto vienen dadas por la integración de todos los elementos que lo integran, incluyendo la escultura. Esta no debía ser algo meramente decorativo, sino un elemento que dotase de sentido al proyecto.

Los autores del jardín decidieron la temática de las esculturas, que hacen referencia a los contenidos y funciones del edificio de la CAC que está frente a las mismas. Estas se agrupan en tres temas genéricos: las artes escénicas, la pretecnología y la vida marina. Para su realización, los autores del proyecto buscaron a dos artistas valencianos: Lucas Karrvaz y Toni Mari, que hicieron quince obras cada uno, y se colocaron en tres fases durante los años 1999 y 2005.

\footnotetext{
${ }^{3}$ SEGUÍ, J. R. (1992) La escultura que hizo Per kirkeby en el cauce del río para el IVAM se utiliza como basurero. Artículo publicado el 7 de noviembre de 1992 en el Levante, p 68

${ }^{4}$ Movimiento-Inercia fue un intercambio artístico organizado por el Departamento de Escultura de la Facultad de Bellas Artes de la UPV junto a otras instituciones europeas. El evento estuvo enmarcado dentro del programa Kaleidoscopio de la Comunidad Europea.
} 


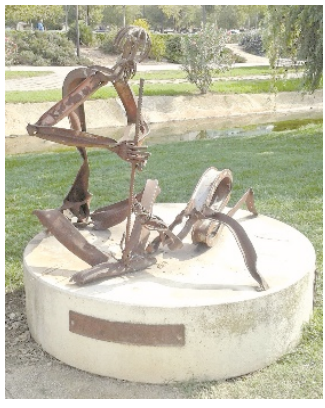

El fuego. Lucas Karrvaz, 1999/2005.

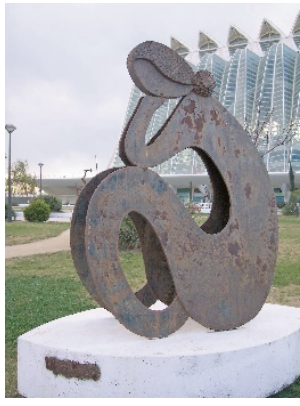

La pensadora. Toni Marí, 1999/2005.

Paralelamente a esta intervención escultórica, la Conselleria de Cultura junto con la empresa gestora de la Ciudad de las Artes y las Ciencias, crea en 1998, el Comité Parque Escultórico del Umbracle. Este organismo tuvo como objetivo, integrar un proyecto escultórico en dicho complejo, y seleccionar a los artistas que elaborarían las esculturas que albergaría el jardín del Umbracle. Los elegidos fueron Ramón de Soto, Joan Cardells, Miquel Navarro, Francesc Abad, Nacho Criado y Yoko Ono. Cada artista tendría una obra que se dispusieron a lo largo del jardín durante la segunda mitad del 2000. Las piezas comparten los principios del arte conceptual, y su estética está en consonancia con las arquitecturas vanguardistas del complejo en el que se encuentran. Posteriormente, se añadió otra escultura en bronce que representa el busto de una mujer alada, de la que se desconoce su autoría y fecha de adquisición.

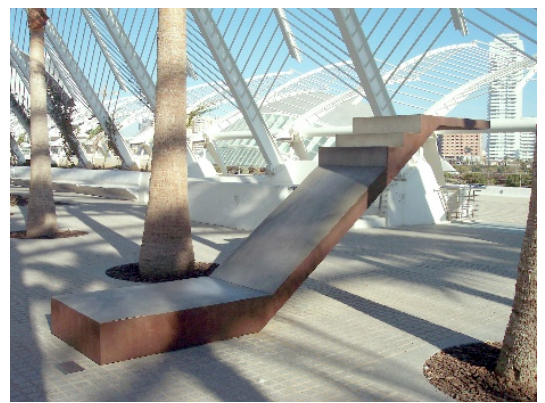

Acceso. Ramón de Soto, 2000.

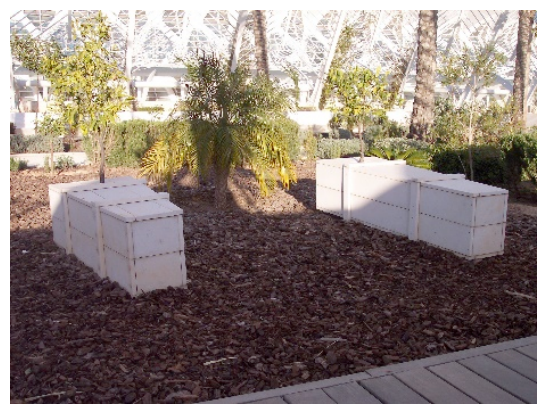

Ex It. Yoko Ono, 2000.

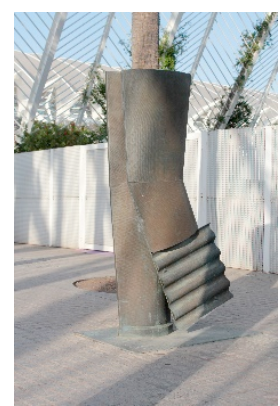

Sin título. Joan Cardells, 2000.

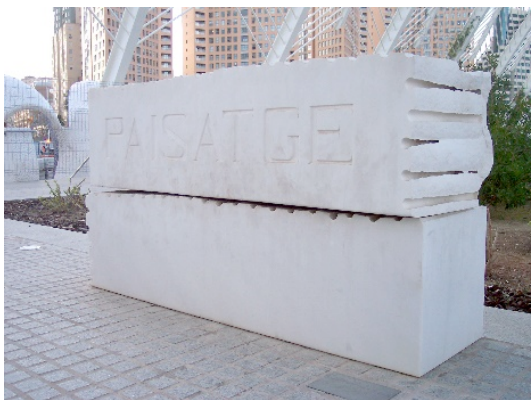

Paisatge. Francesc Abad, 2000. 


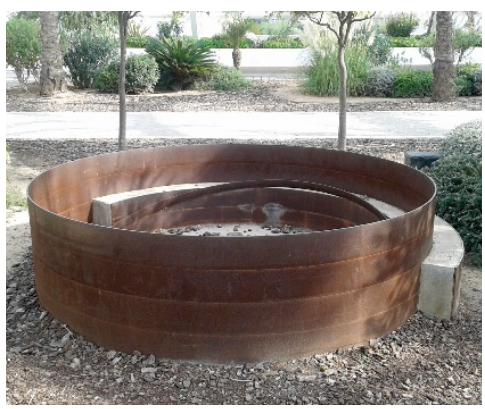

La cristalización de la sequía. Nacho Criado, 2000.

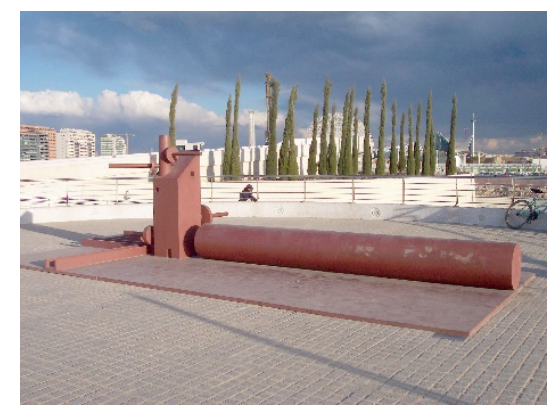

Motoret. Miquel Navarro, 2000.

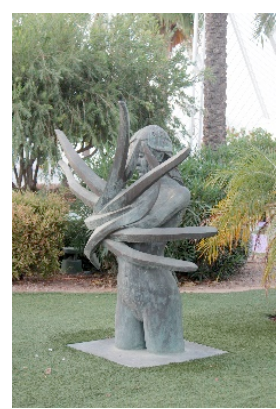

Busto mujer alada.

Artista desconocido, Sin fecha.

Entre los años 2002 y 2003, se remodela el tramo VII, ubicado frente al museo San Pio V. Su diseño estaría pensado para acoger en un futuro, un museo de esculturas al aire libre. Este proyecto artístico se conocería con el nombre de Parque escultórico del antiguo cauce del río Turia, y las primeras esculturas instaladas en este tramo son fruto de dos convenios, que supusieron dos nuevas intervenciones escultóricas en el viejo cauce. En el primer acuerdo, estuvieron implicados el Ayuntamiento de Valencia y la Conselleria de Cultura a través de la Dirección general del Libro y Bibliotecas. Este último envía en 2004 un escrito al Consistorio argumentando que, ante la remodelación que se va a llevar a cabo en la explanada del Monasterio de San Miguel de los Reyes, necesitan trasladar algunas de las esculturas que allí se encuentran. Dichas esculturas fueron realizadas por sus autores específicamente para dicho lugar con el libro y la lectura como tema común. Una de estas obras es El lugar de la memoria de Natividad Navalón, que se cede al Ayuntamiento para que fuese instalada en febrero de 2007 en el tramo VII, sirviendo de arranque al proyecto del Parque escultórico del antiguo cauce del río Turia ${ }^{5}$.

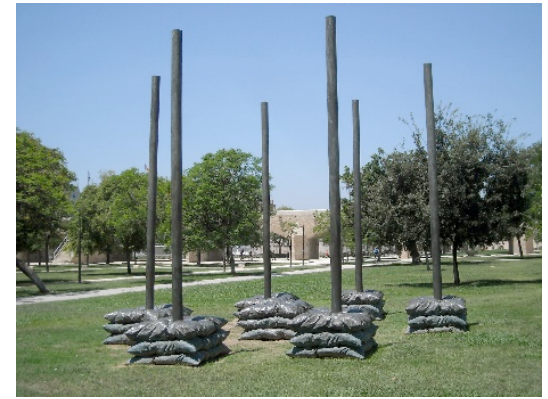

El lugar de la memoria. Natividad Navalón, 2003.

\footnotetext{
${ }^{5}$ Expediente 02001/2004/110 del Servicio de Patrimonio Histórico y Cultural sección Monumentos del Ayuntamiento de Valencia.
} 
Paralelamente a estos hechos, se gesta el segundo convenio entre el IVAM y el Ayuntamiento de Valencia para la cesión de dos esculturas de Gerardo Rueda al mismo proyecto escultórico. Las obras en cuestión fueron Rosario y Cubo, que se exhibieron en una retrospectiva del artista organizada por el IVAM en 2006, y en febrero de 2007, se trasladan desde la explanada del IVAM al tramo VII, coincidiendo con la instalación de la escultura de Navalón 6 .

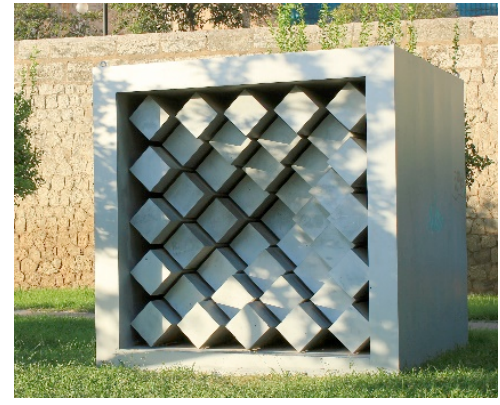

Cubo. Gerardo Rueda, 2006.

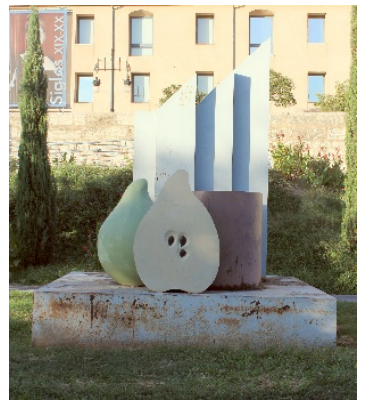

Rosario. Gerardo Rueda, 2006.

Tras la colocación de las obras de Rueda y Navalón, en mayo de 2008, se procedió a la instalación de una nueva pieza en el mismo tramo. La obra es un monumento que tiene como título El principio del fin del cáncer de cuello de útero y sus autoras son Alba Odeh y Patxa Ibarz. La adquisición de la escultura fue el resultado de la elección de Valencia como ganadora de un concurso que tenía como objetivo elegir la ciudad que acogería dicho monumento en uno de sus parques ${ }^{7}$.

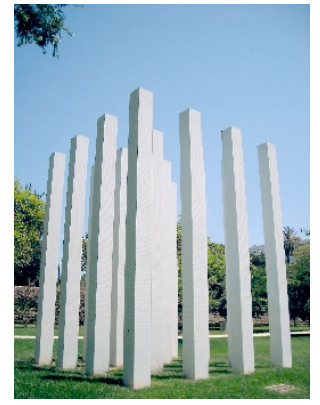

El principio del fin del cáncer de cuello de útero.

A. Odeh y P. Ibarz, 2008.

La colocación de este monumento es la novena y última actuación en el viejo cauce del río Turia llevada a cabo entre los años 1973 y 2014, con un total de 49 esculturas de carácter permanente realizadas por 17 artistas nacionales e internacionales.

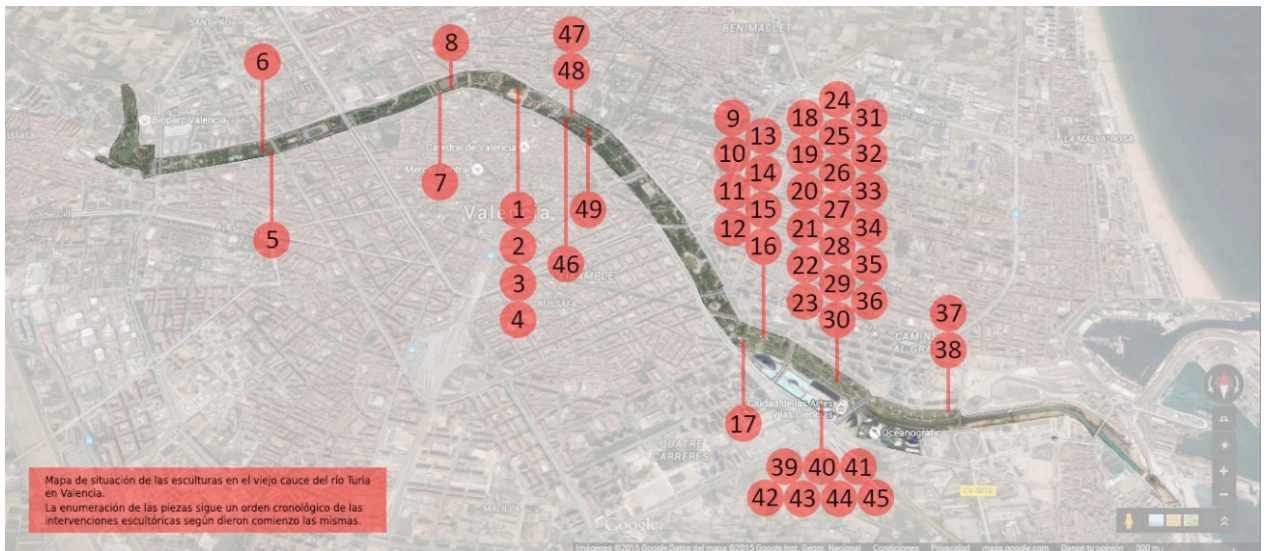

\footnotetext{
${ }^{6}$ Expediente 02001/2006/530 del Servicio de Patrimonio histórico y Cultural sección Monumentos del Ayuntamiento de Valencia

${ }^{7}$ Expediente 02401/2008/468 del Servicio de Sanidad del Ayuntamiento de Valencia.
} 
1. El viejo, 1973. Silvio Moraira. Tramo VI. 2. La cara, 1973. Silvio Moraira. Tramo VI.

3. La mujer, 1973. Silvio Moraira. Tram

4. La tortuga, 1973. Silvio Moraira. Tramo VI.

5. Taulatetombant, 1987. Artur Heras. Tramo II

6. La fonteta de la veritat, 1987

Artur Heras. Tramo II.

7. Sin título, 1989. Per Kirkeby. Tramo V

8. Banco, 1996. Claudia Ammann. Tramo V.

9. El director zurdo, 1999/2005. Lucas Karrvaz. Tramo XIV.

10. Rosa I, 1999/2005. Lucas Karrvaz. Tramo XIV.

11. Rosa II (con insecto), 1999/2005. Lucas Karrvaz. Tramo XIV.

12. Piano, piano, 1999/2005. Lucas Karrvaz. Tramo XIII.

13. Soprano, 1999/2005. Lucas Karrvaz. Tramo XIII.

14. Tenor, 1999/2005. Lucas Karrvaz. Tramo XIII.

15. Flautista, 1999/2005. Lucas Karrvaz. Tramo XIII.

16. Equilibrio / Danzarin, 1999/2005. Toni Marí. Tramo XIII.

17. Neptuno, 1999/2005. Toni Marí. Tramo XIV.
18. El fuego, 1999/2005. Lucas Karrvaz. Tramo XIV. 19. El pastor, 1999/2005. Lucas Karrvaz. Tramo XIV. 20. Aliados, 1999/2005. Lucas Karvaz. Tramo XIV.

21. La siesta, 1999/2005. Lucas Karrvaz. Tramo XIV

22. El espantapájaros, 1999/2005. Lucas Karrvaz. Tramo XIV.

23. La siega, 1999/2005. Lucas Karrvaz. Tramo XIV.

24. El Ilanto, 1999/2005. Lucas Karrvaz. Tramo XIV.

25. Las inclemencias. 1999/2005. Lucas Karrvaz. Tramo XIV.

26. La caza, 1999/2005. Lucas Karrvaz. Tramo XIV.

27. La escritura, 1999/2005. Toni Marí. Tramo XIV.

28. El pescador, 1999/2005. Toni Marí. Tramo XIV.

29. La pesadora, 1999/2005. Toni Marí. Tramo XIV.

30. Toro, 1999/2005. Toni Marí. Tramo XIV.

31. El forjador, 1999/2005. Toni Marí. Tramo XIV.

32. La danza, 1999/2005. Toni Marí. Tramo XIV.

33. Flamencos, 1999/2005. Toni Marí. Tramo XIV.

34. Andante, 1999/2005. Toni Marí. Tramo XIV.

35. La cantarera, 1999/2005. Toni Mari. Tramo XIV.
36. Azada, 1999/2005. Toni Marí. Tramo XIV

37. Banco de peces I, 1999/2005. Toni Marí. Tramo XIII.

38. Banco de peces II, 1999/2005. Toni Mari. Tramo XIII.

39. Acceso, 2000. Ramón de Soto. Umbracle.

40. Paisatge, 2000. Francesc Abad. Umbracle.

41. Sin título, 2000. Joan Cardells. Umbracle.

42. Ex It, 2000. Yoko Ono. Umbracle.

43. La cristalización de la sequía, 2000. Nacho Criado. Umbracle.

44. Motoret, 2000. Miquel Navarro. Umbracle.

45. Busto de mujer alada, $\sin$ año. Autor desconocido. Umbracle.

46. El lugar de la memoria, 2003. Natividad Navalón. Tramo VII.

47. Cubo, 1970 (2006). Gerardo Rueda. Tramo VII.

48. Rosario, 1992 (2006). Gerardo Rueda. Tramo VII.

49. El principio del fin del cáncer de cuello de útero,

2008. Alba Odeh y Patxa Ibarz. Tramo VII.

Las intervenciones escultóricas aquí descritas, son el resultado de una serie de conductas y propósitos de distinta índole, que revelan diferentes formas de proceder y entender el espacio en el que se encuentran, a través del arte como instrumento o pretexto. Además, habría que sumar también otros factores como el contexto social y político del momento en que se dieron estos hechos.

El relato sobre las intervenciones escultóricas del viejo cauce del Turia nos descubre unos modos de proceder, que podemos agrupar en tres tipos: las actuaciones al margen de los proyectos oficiales; los planes y proyectos institucionales, y los proyectos de ajardinamiento que han contado en su diseño con la escultura.

Del primer grupo surgen las esculturas de Silvio Moraira y Claudia Ammann. Ambas intervenciones se llevan a cabo fuera de todos los protocolos institucionales y con una notable circunspección. En el caso de Moraira existe un cierto paralelismo entre el propósito del escultor y las manifestaciones espontáneas en torno a la polémica sobre la especulación del viejo cauce. Estas estuvieron abiertas a todo aquél que quisiese sumarse al sentir popular, que al calor de los acontecimientos, aquel estudiante quiso, mediante una acción artística, contribuir de forma voluntaria y discreta a la consumación del deseo de aquellas personas. Asimismo, la obra de Ammann es también fruto de la ilusión y el altruismo. Este banco yace como un elemento anónimo que, con su aspecto inacabado, parece sugerir acerca de su significación, sobre lo que es o podría haber sido. Es una pieza que por el mismo sigilo que desprende su presencia, pasa casi desapercibida en el entorno.

Al segundo grupo pertenecen las intervenciones gestadas desde las diferentes instituciones públicas con las que se instalan las esculturas de Kirkeby, Rueda, Navalón y el monumento de Alba Odeh y Patxa Ibarz, además de las piezas que acoge el Parque Escultórico del Umbracle. A pesar de ser proyectos ambiciosos inicialmente, las obras nunca se exhibieron como tal, y su estado de conservación en muchas de ellas es más que precario. Aquí cabe señalar el caso de la construcción de Kirkeby, que se erigió como la primera gran escultura de un espacio con ciertas aspiraciones, y su destino ha sido caer en el más absoluto de los olvidos institucionales, que ha devenido en un estado lamentablemente ruinoso de la obra. Llama también la atención la obra de Yoko Ono instalada en el Umbracle, y que actualmente pasa completamente desapercibida entre el mobiliario del bar de copas en el que se ha convertido parte de este paseo ajardinado.

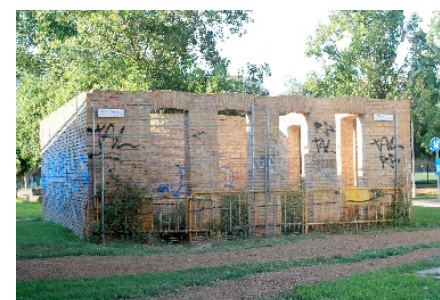

Imagen que presentaba la obra de Kirkeby en 2014.

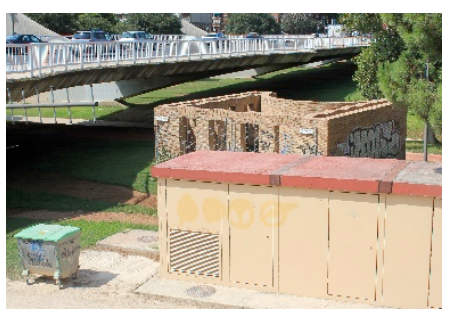

Entorno en el que se encuentra actualmente la obra de Kirkeby, donde diversos elementos han invadido el espacio de la pieza dificultando su observación.

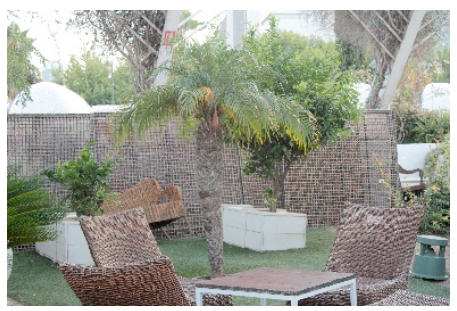

Estado en el que se encuentra en 2014 la escultura Ex It de Yoko Ono en el interior del recinto del bar de copas L'Umbracle, donde los dos féretros se ven rodeados de mobiliario perteneciente a la terraza. 
En el tercer y último caso, se encuentran los proyectos de remodelación del viejo cauce, que han contado con la escultura como parte integrante en sus diseños. Aquí se incluyen las fuentes de Artur Heras y las obras de los escultores Lucas Karrvaz y Toni Marí. Sin embargo, el nivel de implicación del artista en cada uno de los proyectos, así como el grado de integración de las esculturas en el entorno no ha sido el mismo. En el caso de las obras de Heras, se trata de un trabajo cooperativo que busca la convergencia de conocimientos, aportados entre los autores del proyecto de ajardinamiento y el artista. Sin embargo, en la intervención escultórica de los tramos XIII y XIV, la diversa temática de las esculturas - la ópera, la pretecnología y el mundo marino -, poco tiene que ver con la idea de recuperar la memoria del río. Bajo el tratamiento naturista en el diseño del parque, la función de las esculturas es la de correlacionar dos ambientes, el jardín donde se ubican y el complejo arquitectónico de la Ciudad de las Artes y las Ciencias, que son en concepto antagónicos. Además, la participación de los escultores en dicho proyecto, se ciñe en dar respuesta a las voluntades y necesidades creadas de antemano por los autores del diseño.

Tras estos hechos se deduce, que las intervenciones escultóricas llevadas a cabo en el viejo cauce del Turia durante el proceso de remodelación, son consecuencia de acciones circunstanciales que han puesto de manifiesto la ausencia de un plan de acción gestionado de manera reflexiva. Intervenir en el espacio urbano, entraña una complejidad ante la diversidad de actores y formas de entenderlo y ocuparlo, y por ello, las distintas intervenciones llevadas a cabo en este espacio durante los cuarenta años de remodelación han traído como resultado un amalgama de esculturas que oscilan de lo relevante al anonimato. Además, el interés inicial que despertaron las intervenciones escultóricas ha dado paso con el tiempo, a una decadencia que afecta a la conservación y exhibición de las obras. Quizás, llegado el momento, habría que detenerse y abrir un debate reflexivo sobre lo que se ha hecho y el sentido que se pretende conferir en un futuro a la escultura pública en el espacio urbano, y específicamente en la ciudad de Valencia.

\section{FUENTES REFERENCIALES.}

Expediente 194/89 del Servicio de Patrimonio del Ayuntamiento de Valencia. Asunto: Autorización al IVAM para la instalación con carácter definitivo de una escultura en el tramo IV del Jardín del Turia. Año 1989.

Expediente 02001/2006/530 del Servicio de Patrimonio histórico y Cultural sección Monumentos del Ayuntamiento de Valencia. Asunto: Acuerdo de colaboración entre Ayuntamiento y el IVAM sobre la cesión en depósito de dos esculturas de Gerardo Rueda para su ubicación en el cauce del río frente al Museo San Pio V. Año 2006.

Expediente 02001/2004/110 del Servicio de Patrimonio Histórico y Cultural sección Monumentos del Ayuntamiento de Valencia. Asunto: Convenio entre la Generalitat valenciana y el Ayuntamiento de Valencia para la cesión temporal de las esculturas "Homenaje del libro" y "El lugar de la memoria". Año 2004.

Expediente 02401/2008/468 del Servicio de Sanidad del Ayuntamiento de Valencia. Asunto: Invitación a participar en el concurso para selección de emplazamiento a monumento referido al cáncer de útero. Año 2008.

FENOLL PELLín, A. La escultura pública en el proceso de remodelación del viejo cauce del rio Turia en Valencia, 1973-2014. Tesis doctoral . Universitat Politècnica de València. Valencia, 2015.

SEGUÍ, J. R. (1992) La escultura que hizo Per kirkeby en el cauce del río para el IVAM se utiliza como basurero. Artículo publicado el 7 de noviembre de 1992 en el Levante, p 68. 